\title{
DECODING SPATIOTEMPORAL PATTERNS OF URBAN LAND SPRAWL IN ZHUHAI, CHINA
}

\author{
LI, L. Y. ${ }^{1}-$ QI, Z. X. $.^{2 *}-$ XIAN, S. ${ }^{3}$ \\ ${ }^{1}$ Department of Urban Planning, College of Architecture and Urban Planning, Tongji \\ University, Shanghai 200092, China; e-mail: lilingyue929@gmail.com \\ ${ }^{2}$ Guangdong Provincial Key Laboratory of Urbanization and Geo-simulation, School of \\ Geography and Planning, Sun Yat-sen University, Guangzhou 510275, China \\ ${ }^{3}$ School of Geographical Sciences, Guangzhou University, Guangzhou 510006, China \\ ${ }^{*}$ Corresponding author \\ e-mail: qizhixin@mail.sysu.edu.cn; phonelfax:+86-20-84115833
}

(Received 13 $3^{\text {th }}$ Jul 2019; accepted $25^{\text {th }}$ Nov 2019)

\begin{abstract}
Urban sprawl is a major factor that threatens the loss of arable landmass, and its evolving morphology has long interested numerous scholars. However, existing research on this study has not been concerned with the cases of ordinary cities, particularly their intra-urban land and urban sprawl. This study goes beyond mega-/super-cities and takes Zhuhai, an ordinary large city in China's Pearl River Delta (PRD) region, as a case. Through remote sensing and GIS technology, this research identifies the increasing built-up areas and its sub-typologies (infill, outlying and edge-expansion), distinguishes the reclamation area and the decreasing arable landmass and evaluates the rate of land-use inside its five districts from 1980 to 2015. The growth of urban areas and loss of arable landmass are uneven inside Zhuhai. The most uneven outlying and infill growth were observed from 1990 to 1995 and from 2013 to 2015, respectively. Edge-expansion is the least imbalanced typology and reached its minimum from 2010 to 2013. The extent of variability of the total urban sprawl generally accords with that of edge-expansion and imbalance of arable landmass loss that reached a peak from 2005 to 2008. However, policy, planning and other factors that matter in urban sprawl are also discussed.
\end{abstract}

Keywords: land reclamation, arable land loss, variability, Landsat, ArcGIS

\section{Introduction}

The term sprawl originated from the U.S. and its rapid suburbanisation (Leichenko and Solecki, 2014). However, the definition of urban sprawl varies among researchers and policymakers as this politically charged terminology lacks precision in the narrative of policy documents. In addition, the characteristics of sprawl differ from place to place (e.g. Sprawl in American cities is much less dense than that in Asian cities) (Shahraki, 2011; Hamidi and Ewing, 2014). Thus, contextualised case studies, especially from the global South, are needed to offer insights. In this research, we specifically deploy urban land sprawl denoting the adjacent sprawl of urban land, away from existing built-up area to undeveloped rural area. With the breakthrough of urban margins, this type of urban activity is often criticised for encroaching arable land, causing environmental degradation and undermining the natural landscape. Thus, sprawl represents an uncoordinated growth without thinking about the random effects, the additive urban growth that results in inefficient resource utilisation and ecological destruction (Bhatta et al., 2010). This unsustainability has already been revealed in fast-expanding cities. For instance, in India, under unprecedented urban sprawl, land use has changed rapidly in fringe towns and cities along the rapid transportation corridor (Theobald, 2001). Indicators used to identify urban 
sprawl include the loss of arable landmass and forest habitat and the increase of impervious surface.

Urban sprawl is a spatial process along with complex changes in land use (Bhatta et al., 2010). This process is influenced by urban policy and planning. Urban sprawl morphology and its spatiotemporal characteristics have attracted the attention of scholars. Old theories, such as concentric zones and sectors and multiple nuclei theories (Burgess, 1925; Hoyt, 1939; Harris and Ullman, 1945) are unable to capture long-term and multi-temporal sprawl patterns. Recent research has benefitted from the advancement of remote sensing. However, data assemblage and interpretation have always been an enormous task before quantifying land-use change (Batty, 2002; Herold et al., 2003; Peng et al., 2010; Xian et al., 2019). Moreover, researchers have focused on the sprawl patterns of cities (especially mega cityregions) across macro-scale regions, nations and even the world (Grainger, 1995; Li et al., 2004; Hamidi and Ewing, 2014; Scheuer et al., 2016; Li and Li, 2019; Aniekwe and Igu, 2019). For instance, Hamidi and Ewing (2014) have stated that the growth of infill increases the density of metropolitan areas (often in coastal areas). However, they have identified that the density of urbanised areas in the U.S. decreases with the increase of metropolitan sprawl between 2000 and 2010, leading to overuse of automobiles. In an up-to-date study exploring the spatiotemporal patterns of urban sprawl in China from 2006 to 2014 ( $\mathrm{Li}$ and Li, 2019), the growth rates of built-up areas outweighing the population are most significant in the Western region, followed by the Eastern and Central regions and least significant in the Northeast. The rates of urban sprawl in mega and super cities are minimum, sometimes even negative. However, these rates are still notable in large and medium cities. The sprawl is also found related to population and economic growth. Nevertheless, the manner in which ordinary, large, medium and small cities sprawl, including the patterns and typologies in intra-urban sprawls, remains unclear. Do these cities sprawl with different patterns or rules? How does sprawl take place inside the city? What are the specific causes?

This current study aims to address the questions by giving special attention to the volume, structure and forms of land use (Long and $\mathrm{Li}, 2012$ ). Furthermore, the trend, rates and variability of urban land sprawl in a non-mega-/super-city is examined. Zhuhai, located in the Southern coast China, is selected as the study area for two main reasons. Firstly, urban China is an interesting subject matter, exhibiting different sprawl patterns from the American model. These patterns are revealed in numerous up-to-date studies (Chen, 2016; You, 2016; Ding and Wang, 2018; Yang et al., 2018; Liu, 2020). Secondly, different from mega-/super-cities (according to the National Statistical Bureau, cities with permanent residents more than 10 million are megacities; between 5 and 10 million are super cities; between 1 and 5 million are large cities; between 500 hundred thousand and 1 million are medium cities and fewer than 500 hundred thousand are small cities), Zhuhai is a large city embracing a green environment and eco-city ideology. From a small county to a sizable metropolis, the specific trajectory and forms of sprawl can update existing understanding beyond economic star megacities, e.g. Shenzhen, Guangzhou, and Shanghai. However, in what patterns city grows is still unclear. Unravelling the spatiotemporal transition of land can provide a comprehensive picture and produce invaluable implications for the ongoing urban development in China. Using Zhuhai as a case, this research distinguishes and quantifies different land use (e.g., urban built-up area and arable land); evaluates the rate of land-use change to economic and population growth; measures the extent of sprawl variability and discusses how policy, planning and other factors matter in urban sprawl. Edge-expansion, outlying, and infilling as different sprawl typologies of built-up area are also computed (Budd, 1996; Liu et al., 2010; Shi et al., 2010). 


\section{Materials and methods}

\section{Area of research}

Zhuhai, known as a city of hundred islands, has been reputed for its appeal, windy coastline, diverse tropical vegetation, green ambiance for liveability and stretched urban structure in Pearl River Delta (PRD) in China. Adjacent to Jiangmen, Zhongshan and Macau, Zhuhai is situated at the estuary of South Guangdong (Fig. 1). The city has Xiangzhou, Doumen, Jinwan districts under its jurisdiction. Gaoxin district, which are known as the city's High-tech Zone, and Hensqin vitalise local economic growth. Zhuhai is a typical fast-growing immigrant city evolving from a traditional Cantonese-speaking region of Guangdong province to a Mandarin-based area with a large influx of immigrants from inland provinces.

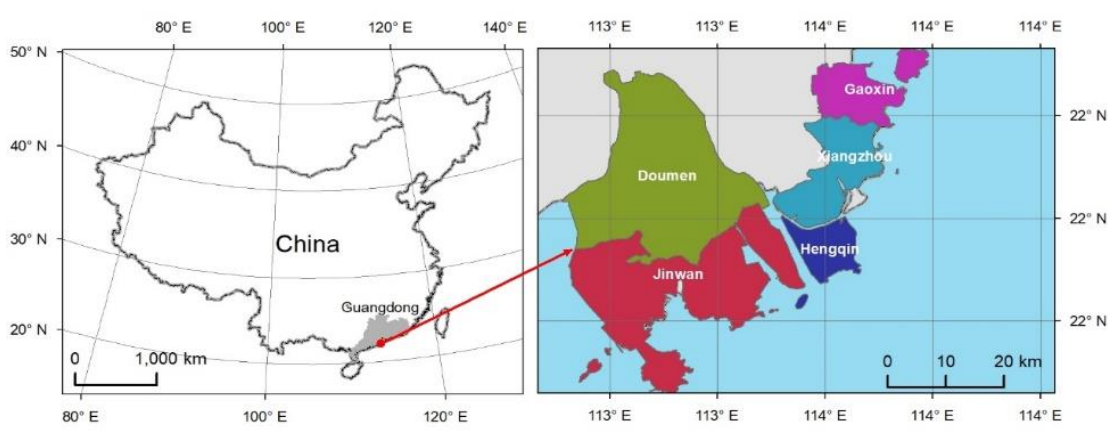

Figure 1. Zhuhai's Location and its districts

\section{Data sources}

Land cover and land-use change identification are essential for ecological environment analysis and planning. The information is commonly extracted from satellite images by using supervised classification methods, which require classified reference samples to train the classifier and subsequently classify unknown data (Qi et al., 2012). Given the availability of the data and pre-research on Zhuhai, remote sensing images spanning nine years from Landsat satellites are acquired from the United States Geological Survey, with a time span of 35 years (Table 1). Except for the earliest 1980 image provided by the Multispectral Scanner Sensor (MSS), which have $78 \mathrm{~m}$ coarse resolution, the rest of the images of the Thematic Maps (TM) and Operational Land Imager (OLI) all have $30 \mathrm{~m}$ resolution.

Table 1. Dataset of landsat images

\begin{tabular}{c|c|c|c}
\hline Acquisition time & Satellite & Sensor & Resolution (m) \\
\hline $\mathbf{1 9 8 0}$ & Landsat-3 & MSS & 78 \\
$\mathbf{1 9 9 0}$ & Landsat-5 & TM & 30 \\
$\mathbf{1 9 9 5}$ & Landsat-6 & TM & 30 \\
$\mathbf{2 0 0 0}$ & Landsat-7 & TM & 30 \\
$\mathbf{2 0 0 5}$ & Landsat-5 & TM & 30 \\
$\mathbf{2 0 1 0}$ & Landsat-5 & TM & 30 \\
$\mathbf{2 0 1 3}$ & Landsat-7 & TM & 30 \\
$\mathbf{2 0 1 5}$ & Landsat-8 & OLI & 30 \\
\hline
\end{tabular}

As the expansion rate became increasingly rapid, the later the periods, the shorter the time, such that the urban land change can be accurately captured 


\section{Methods}

\section{Identifying land use types}

Diverse methods are used to determine the different types of land use. In this research, support vector machines (SVMs) (Chang and Lin, 2011), which are one of the most widely used supervised classifiers, are used for Landsat image classification to extract land cover information. Radial basis function (RBF) is selected as the mapping kernel of SVM. A grid search strategy is used to derive the optimal parameters of the RBF kernel SVM (Chang and Lin, 2011). To collect ground truth data in assessing the accuracy of identifying urban sprawl features, fieldwork is conducted using high-resolution Google Earth images. Based on experience with multinomial distribution (Congalton and Green, 2009), a minimum of 50 samples are collected for each land cover class. Different categories of land use are identified. The built-up area is the main parameter quantifying urban sprawl (Shahraki, 2011). Reclamation is a special parameter to complement the understanding of coastal urban expansion. The built-up area is visually interpreted through the software of ArcMap and reviewed by qualified technicians (Akbari et al., 2003) as visual form performs better than spectral signal in distinguishing land use characteristics. Furthermore, visual form avoids misclassifications and guarantees preciseness.

\section{Evaluating the rate of change}

In assessing the growth of the economy and population relates with urban land sprawl, standardised sprawl efficiency of GDP $\left(\mathrm{LSGDP}_{\mathrm{s}}\right)$ and permanent residents $\left(\mathrm{LSPE}_{\mathrm{s}}\right)$ (calculating the growth rate of the GDP and the permanent resident population to that of urban built-up areas) is applied to each district in different periods. This article also calculates the annual loss rate of arable land, which partially transited to the increase of the built-up areas.

\section{Measuring the extent of variability}

The coefficient of variation $(\mathrm{CV})$ is calculated to reveal the extent of variability in relation to the mean of land sprawl, arable land and forest loss within a city. The CV is defined as the ratio of the standard deviation to the mean value and is calculated as

$$
(C \cdot V)_{i j}=\frac{S_{i j}}{\bar{X}_{i j}} \times 100 \%, S_{i j}=\sqrt{\sum\left(\bar{G}_{i j k}-\bar{X}_{i j}\right)^{2} / n}
$$

where $(C \cdot V)_{i j}$ is the variation score of sprawl/loss type $j$ during time period $i, \bar{X}_{i j}$ and $\mathrm{S}_{i j}$ denote the sample mean and standard deviation of sprawl type $j$ during time period $i$, and $\mathrm{n}$ represents the number of the sample. A larger value of $\mathrm{CV}$ signifies a greater level of dispersion around the mean. Conversely, a smaller value of CV entails a lower level of dispersion around the mean. This research also measures the $\mathrm{CV}$ of different typologies of land sprawl, which are calculated by the Landscape Expansion Index (LEI) (Liu et al., 2010; Xian et al., 2019). In LEI, different value intervals denote various sprawl typologies: newly built patches that spread from the boundary of existent areas are identified as edgeexpansion (0-50). Enclave new patches detaching from the existent areas is categorised as outlying (0). Newly developed urban patch stuffing an existing land parcel is infill (50100). The typologies further detail the sprawl trajectory of the case city. 


\section{Results}

\section{The general trend of urban land sprawl}

The general change of urban land use is identified through visual interpretation based on Landsat data and presented in Fig. 2. The left vertical axes indicate data sets of forest, urban and arable land in square kilometers while the right vertical axes shows urban land per capita (with unit of $\mathrm{km}^{2}$ /person). Among the identified categories, arable land and forest land gradually decrease over time. Until 2015, almost $300 \mathrm{~km}^{2}$ of arable land and $50 \mathrm{~km}^{2}$ of forest land has been encroached, a substantial part of which has turned into urban built-up area. From 1980 to 2015, the proportion of Zhuhai's arable land to the total landmass dropped from $44.64 \%$ to $23.88 \%$, with the urban built-up area expanding to $240.48 \mathrm{~km}^{2}$. The urban built-up area has increased from 35.19 to $275.67 \mathrm{~km}^{2}$, whereas the per capita area has fluctuated significantly, surging from $96.32 \mathrm{~m}^{2}$ in 1980 to $168.53 \mathrm{~m}^{2}$ in 1995 ; this area declined to $144.13 \mathrm{~m}^{2}$ in 2000 and increased again to $169.73 \mathrm{~m}^{2}$ in 2013 (Figs. 2 and 3).

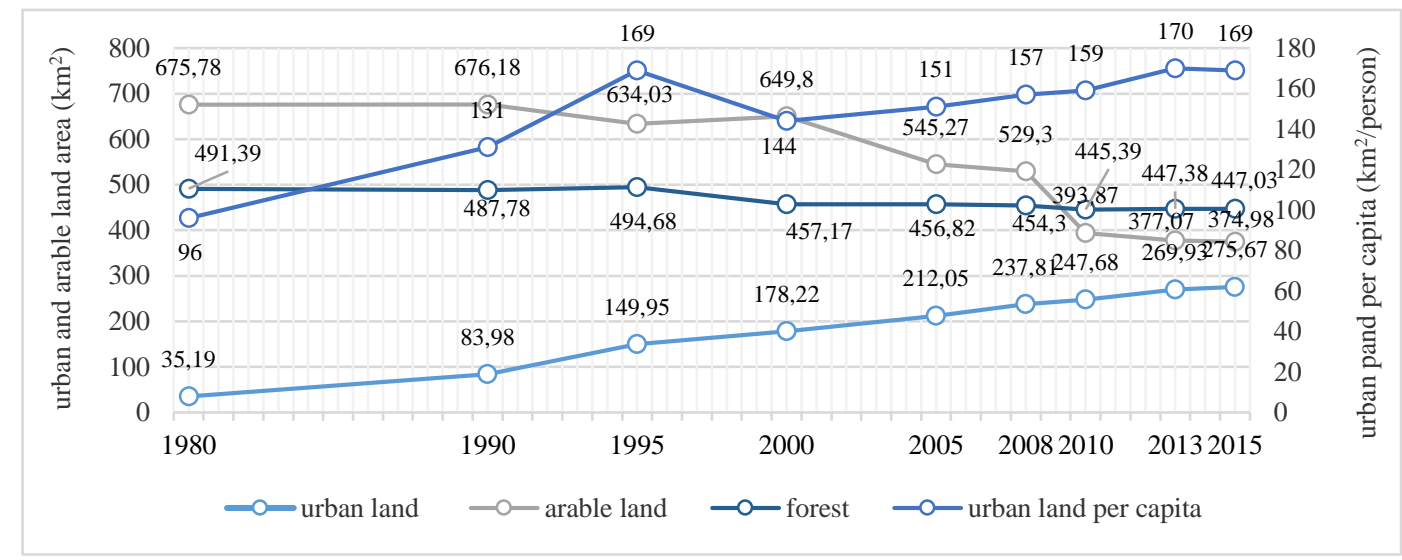

Figure 2. Change of urban and arable land (per capita) in Zhuhai (1980-2015)

The coastline in Zhuhai was reshaped from 1980 to 2015 (Fig. 3). From 1980 to 1990, artificial land reclaimed along the coastlines reached a peak of $108.4 \mathrm{~km}^{2}$, which happened along the Western coast of Jinwan. From 1990 to 1995, reclamation projects decreased but remained considerable at $11.27 \mathrm{~km}^{2}$ in areas scattered around Northeast Hengqin. From 1995 to 2000, Northwest Hengqin and the Western Coast of Jinwan witnessed visible reclamation. However, the amount reduced to $7.35 \mathrm{~km}^{2}$. From 2000 to 2005, the reclamation mainly took place in South Jinwan and North Gaoxin and slightly increased to $8.12 \mathrm{~km}^{2}$. Between 2005 and 2008, lands were reclaimed along the Southwest boast of Jinwan but shrank sharply to $1.45 \mathrm{~km}^{2}$. From 2008 to 2010, three pieces of land up to $10.16 \mathrm{~km}^{2}$ were reclaimed in South Jinwan and Northwest Hengqin. However, from 2010 to 2013, the reclamation area dropped to $8.96 \mathrm{~km}^{2}$. From 2013 to 2015 , these areas were reduced to $0.45 \mathrm{~km}^{2}$, which all occurred in the Jinwan District.

\section{The gains and loss rates of urban land sprawl}

The intra-urban spatiotemporal patterns, the annual sprawl area of Zhuhai and the five districts are calculated (Fig. 4). Jinwan overwhelmingly expanded over 700 ha in 1990 and 1995, 270 ha in 2000 and 2005, 480 ha in 2005 and 2008, 250 ha in 2010 and 2013, 
followed by Xiangzhou, expanding 290 ha in 1980 and 1990, 340 ha in 1990 and 1995, 250 ha in 1995 and 2000. The least sprawled district is Hengqin with a less than 10 ha annual increase before 2010. The annual sprawl areas of Doumen and Gaoxin districts were among the average.
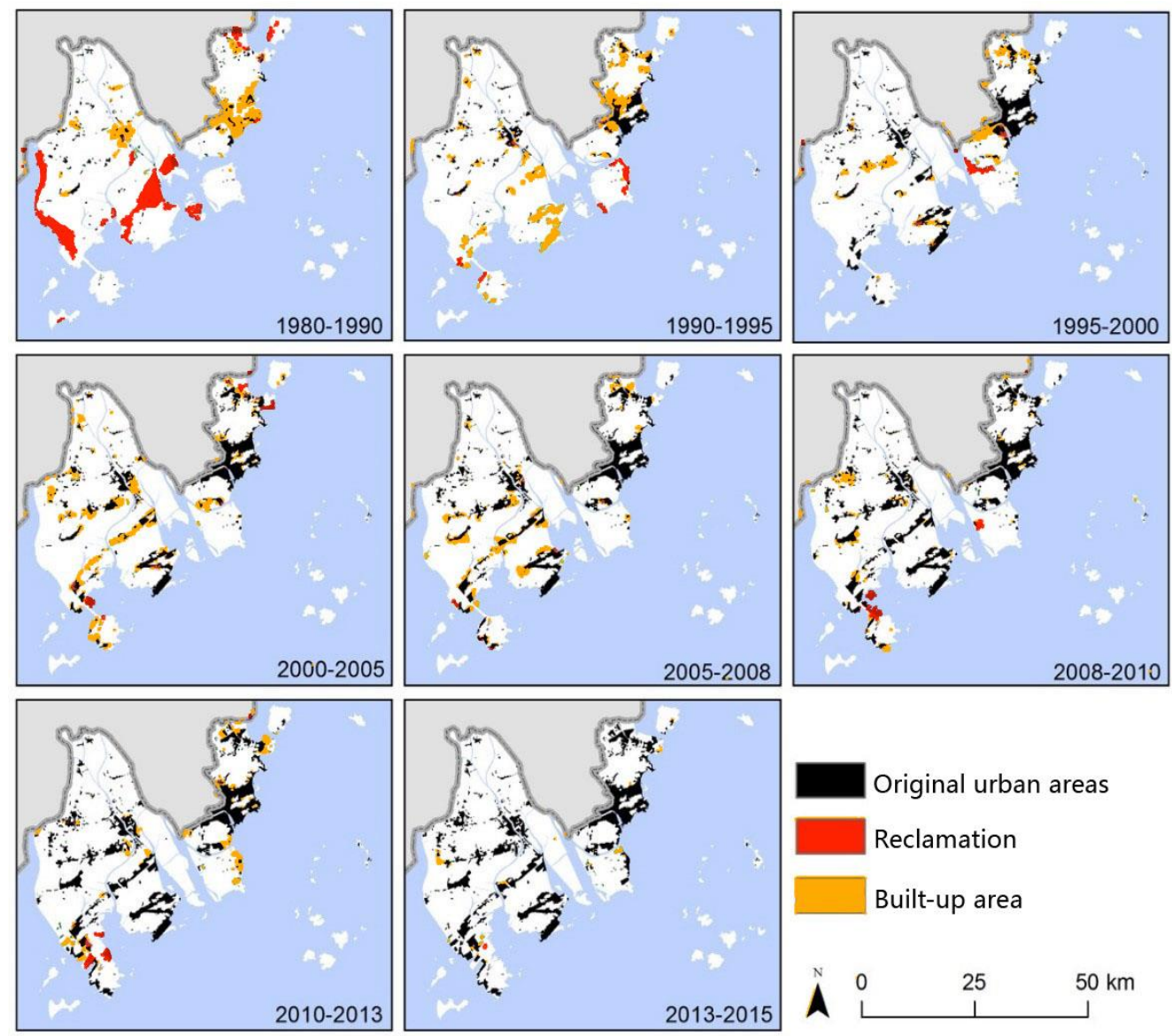

Figure 3. Urban land sprawl and coastal land reclamation in Zhuhai (1980-2015)

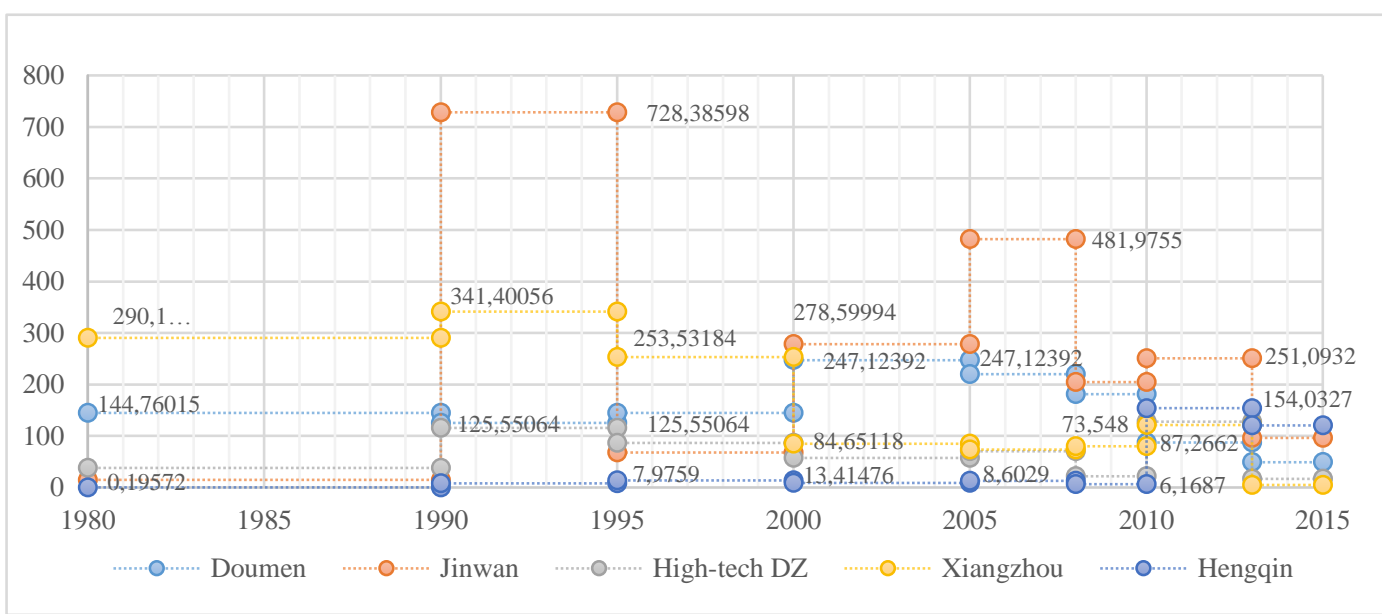

Figure 4. Annual sprawl area of Zhuhai's five districts in eight periods (1980-2015) (unit: hectare) 
LSGDP $_{\mathrm{s}}$ was generally higher than LSPEs during 2008 and 2015. Xiangzhou's LSGDP $_{\mathrm{s}}$ is highest in 2008-2010 (36.66) but declined thereafter (Fig. 5). Jinwan's LSGDP $_{\mathrm{s}}$ declined first in 2010-2013 and increased again in 2013-2015. Doumen's LSGDP $_{\mathrm{s}}$ was negative in 2008-2010 (-0.98) but had a significant increase throughout 2010-2013 (10.87) and 2013-2015 (13.86). All the districts' LSPE decreased in 20102013 and increased in 2013-2015, but Xiangzhou's LSPE $E_{\mathrm{s}}$ in 2008-2010 (6.19) remains most significant and Jinwan's LSPE $\mathrm{s}_{\mathrm{s}}$ is minimum in 2010-2013 (0.13).
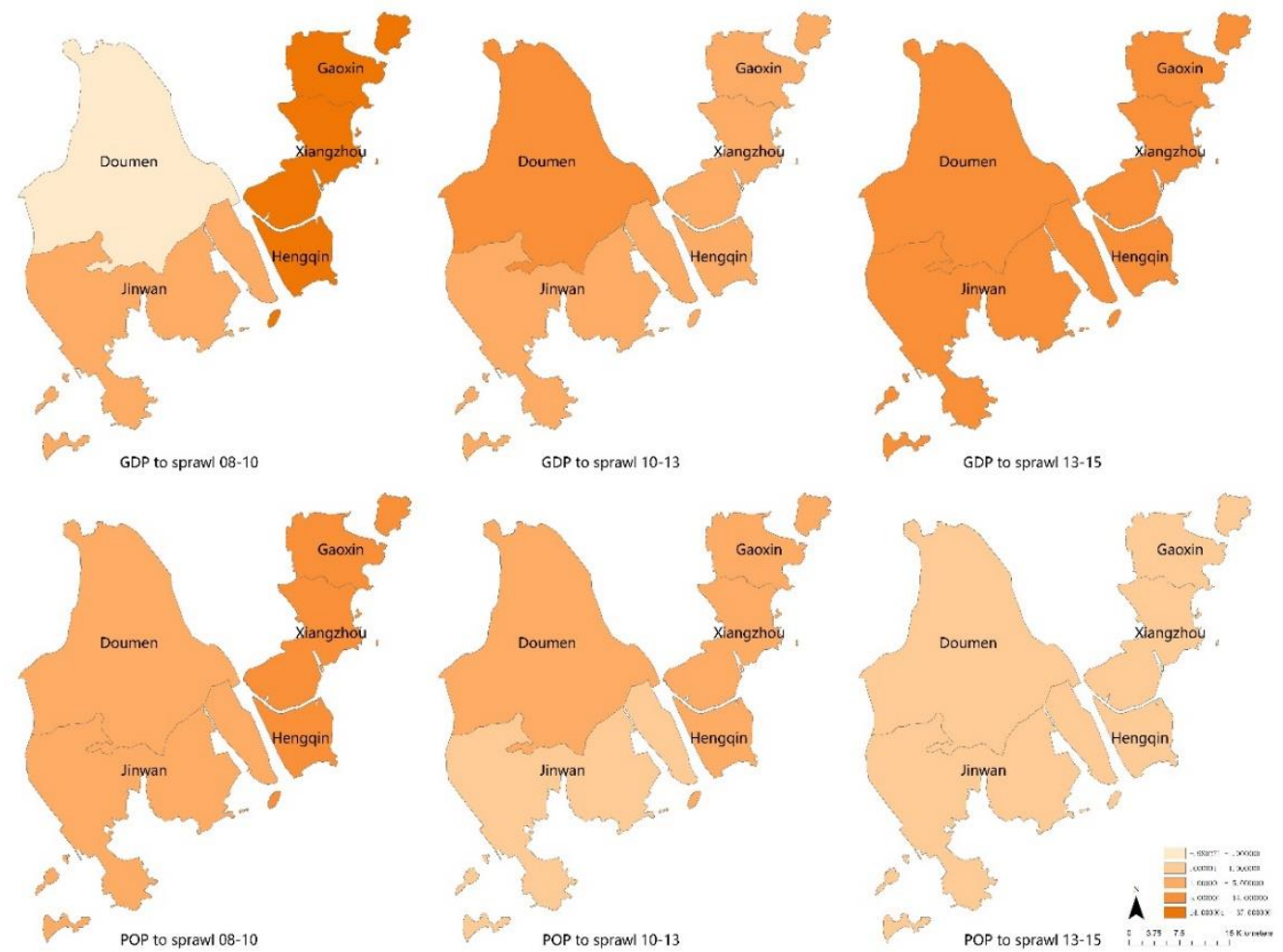

Figure 5. Standard sprawl efficiency of GDP and permanent residents in Zhuhai's five districts (2008-2015)

Loss rate of arable land is greater after 2000 than in previous years but varies across periods and districts (Fig. 6). In Fig. 6, the shallow the colour, the greater loss of the arable land. The most intensive loss of arable land occurred between 2000 and 2005, and 2010 and 2013, with each district losing more than $0.9 \%$ arable land except Gaoxin (20102013). Xiangzhou (1990-1995, -5.17\%; 2008-2010, -11.38\%; 2010-2013, -8.21\%) and Gaoxin (1990-1995, -4.76\%; 2008-2010, -21.73\%) were the top districts that experienced intensive arable land decrease with over a $4.5 \%$ loss rate. Hengqin gained arable lands in 1980-1990 (7.48\%) and 1990-1995 (60.42\%). A similar increase was also observed in Gaoxin (1995-2000, 4.12\%), Doumen (1995-2000, 2.23\%) and Jinwan (1980-1990, 1990-1995, 1.08\%).

\section{Imbalance of urban land sprawl}

From 1980 to 2015, the CV of arable land loss was higher and greater than forest loss (Fig. 7). However, both lands experienced three rounds of increase (1990-1995, 2005-2008, 2013-2015). The lowest value was in 2010 and 2013, with both CVs reaching 
zero, thus indicating a highly balanced loss of arable land and forest. The imbalance of arable loss reached a peak in 2005-2008, with a CV of 0.87 and forest loss in 1990-1995, with a CV of 0.76.
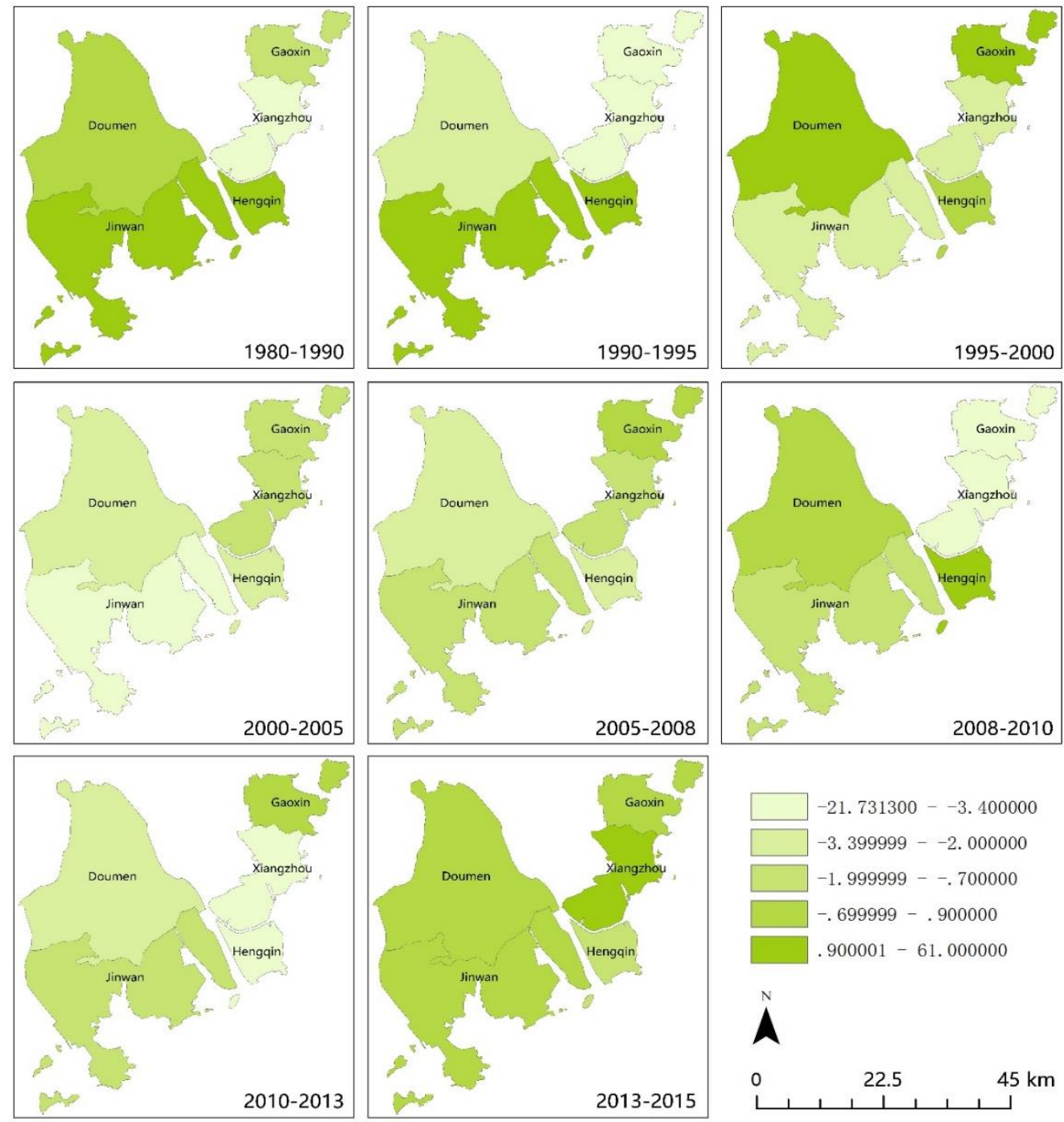

Figure 6. Annual loss rate of arable land in Zhuhai's five districts (1980-2015)

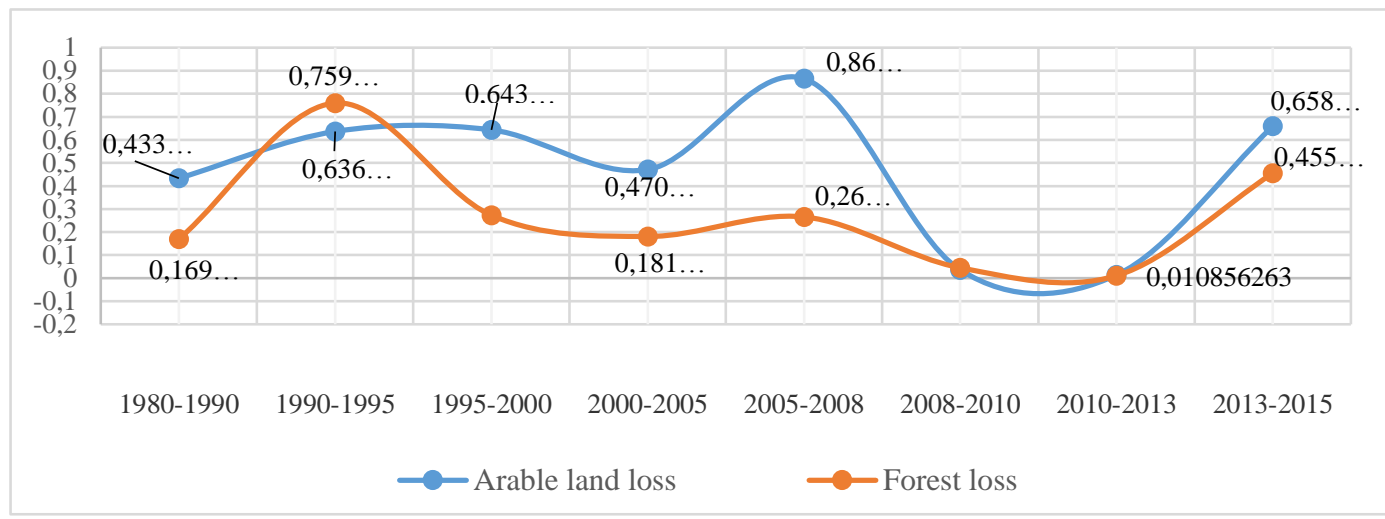

Figure 7. The CV of arable land and forest loss throughout eight periods (1980-2015) 
To get a clearer picture of intra-urban sprawl patterns, sprawl typologies of eight periods in Zhuhai's five districts are explored (Table 2). Edge expansion has played a major role for 35 years and was mainly distributed across former centres of Doumen and Xiangzhou in the initial period. Outlying growth mainly took place in the Jinwan District and surpassed edge expansion in the early 1990s. Though much lesser than the other two types, infill growth was significant from 1995 to 2000, 2000 to 2005 and 2010 to 2013. In addition, this growth occasionally occurred in the Gaoxin District before 2005. Sprawl in Hengqin gained speed in 2010 with edge expansion and outlying growth representing the main types. Three typological sprawls stabilised from 1995 to 2010 . Between 1995 and 2000 , the growth amount decreased to $28.30 \mathrm{~km}^{2}$ with the outlying growth suddenly dropping to $5.47 \mathrm{~km}^{2}$ and hardly increasing in large numbers afterwards. Between 2000 and 2005 , the sprawl area fairly reached $34.1 \mathrm{~km}^{2}$ in which edge expansion and infill growth made up certain vacant spaces along Zhuhai Avenue. From 2005 to 2008, westward sprawl increased with edge sprawl continued completing the main transport corridor. The outlying growth and infill growth supplemented the sprawl but did not take the main role. The subsequent sprawl from 2010 to 2013 and from 2013 to 2015 experienced a downward trend. The edge expansion continued to drop, but the outlying growth became substantial, especially in Hengqin.

Table 2. Sprawling typologies in Zhuhai's different districts (1980-2015) (unit: $\left.\mathrm{m}^{2}\right)$

\begin{tabular}{c|l|c|c|c|c|c|c|c|c}
\hline \multirow{5}{*}{ Doumen } & & $\mathbf{1 9 8 0 -}$ & $\mathbf{1 9 9 0 -}$ & $\mathbf{1 9 9 5 -}$ & $\mathbf{2 0 0 0 -}$ & $\mathbf{2 0 0 5 -}$ & $\mathbf{2 0 0 8 -}$ & $\mathbf{2 0 1 0 -}$ & $\mathbf{2 0 1 3 -}$ \\
& & $\mathbf{1 9 9 0}$ & $\mathbf{1 9 9 5}$ & $\mathbf{2 0 0 0}$ & $\mathbf{2 0 0 5}$ & $\mathbf{2 0 0 8}$ & $\mathbf{2 0 1 0}$ & $\mathbf{2 0 1 3}$ & $\mathbf{2 0 1 5}$ \\
\hline \multirow{5}{*}{ Jinwan } & Outlying & 5184557 & 1189280 & 915297 & 1309671 & 759685 & 880705 & 574847 & 40500 \\
& Edge-expansion & 8913359 & 3630740 & 5838817 & 10323974 & 4776961 & 2672469 & 1446939 & 938700 \\
& Infill & 378099 & 1457512 & 469337 & 722551 & 1072585 & 64060 & 596200 & 0 \\
\hline \multirow{5}{*}{ Gaoxin } & Outlying & 1010176 & 30702779 & 0 & 2526234 & 2702522 & 490649 & 4724333 & $147600 C$ \\
& Edge-expansion & 467954 & 5315060 & 1034900 & 9076057 & 11038427 & 3433755 & 912238 & 218700 \\
& Infill & 2669 & 401460 & 2350281 & 2327706 & 718316 & 170826 & 1896225 & 223200 \\
\hline \multirow{5}{*}{ Xiangzhou } & Outlying & 931459 & 998320 & 788522 & 723320 & 0 & 0 & 696991 & 0 \\
& Edge-expansion & 1757827 & 4225096 & 3397747 & 785622 & 2072209 & 396116 & 3132133 & 333900 \\
& Infill & 1108498 & 576432 & 132170 & 1370461 & 33095 & 30844 & 3417 & 0 \\
\hline & Outlying & 2231989 & 1235465 & 3089352 & 0 & 330952 & 591960 & 259663 & 0 \\
& Edge-expansion & 2678734 & 11942536 & 6805385 & 3768557 & 1309109 & 876399 & 2655624 & 98100 \\
& Infill & 0 & 3892027 & 2781855 & 464002 & 566379 & 134644 & 732011 & 0 \\
\hline \multirow{3}{*}{ Hengqin } & Outlying & 19572 & 383696 & 670738 & 357813 & 54156 & 0 & 2192617 & $241290 C$ \\
& Edge-expansion & 0 & 15099 & 0 & 72332 & 330200 & 122188 & 2428364 & 0 \\
& Infill & 0 & 0 & 0 & 0 & 1504 & 1186 & 0 & 0 \\
\hline \multirow{2}{*}{ Zhuhai } & Total & 4879350 & 65965500 & 28274400 & 33828300 & 25766100 & 9865800 & 22251600 & $574200 C$ \\
\hline
\end{tabular}

The imbalance of infill growth reached its peak (2013-2015) with a CV of 2.24 (Fig. 8). The CV of outlying growth fluctuated the most before 2010 and became the most uneven from 1990 to 1995 with a CV of 1.93 and from 2005 to 2008 with a CV of 1.46. Overall, edge expansion is the least imbalanced growth type and reached its minimum from 2010 to 2013 with a CV of 0.42 . The extent of variability of total sprawl generally accords with that of edge expansion. 


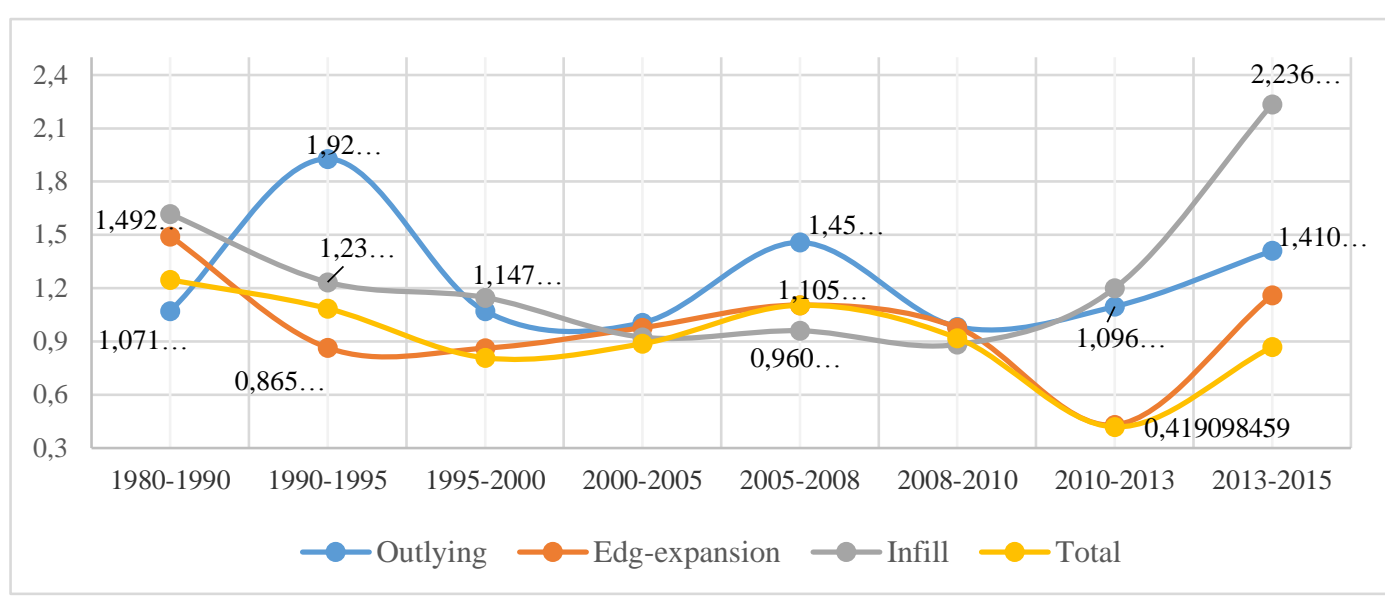

Figure 8. The CV of urban land sprawl throughout eight periods (1980-2015)

\section{Discussion}

\section{Environmental policies/discourses regulating sprawl rates and typologies}

The Zhuhai's remarkable growth and 35-year sprawl is only half of Guangzhou's growth (from 1978 to 2005) and less than 35\% of Shenzhen's (from 1980 to 2010). Loss of arable land is particularly striking in Shenzhen, shrinking from $354.73 \mathrm{~km}^{2}$ in 1979 to $39.77 \mathrm{~km}^{2}$ in 2015 and decreasing to $88.8 \%$ in the same period (Li et al., 2004). Most of Shenzhen's arable land designated for vegetable use became polluted and surrounded by urban areas. The relatively smaller sprawl in Zhuhai is due to its pro-environmental policies/discourses. Zhuhai was prudent in the early 1980s, when numerous PRD cities prioritised industrialisation as their development strategy for economic growth. Balancing the economy and the environment was central to Zhuhai's early development pathway. Having labelled itself as a coastal garden city and favouring tourism as its key industry for development, Zhuhai did not jeopardise its ecological environment. Suppressing industrial development to retain the city's environmental quality and beautiful landscape affected Zhuhai's economy. This phenomenon was reflected not only in the smaller expansion area of its urban land but also in its slower economic growth than its counterparts, such as Shenzhen. Zhuhai's average GDP growth rate was only $20 \%$ of Shenzhen from 1979 to 1984. Similar to Shenzhen, Zhuhai put industrialisation as part of its agenda since 1984 to address the economic backwardness. Zhuhai's GDP began to accelerate, and more than 3,000 cooperative firms were set up. In this period, Zhuhai's urban growth ran into a fast track, and its urban construction land experienced an upsurge until the early 1990s. Similar to other cities in the PRD, Zhuhai's industrialisation had low technology and was labour-intensive, which led to environmental degradation. Manufacturing firms sprouted and contaminated the soil, water and air. Land reclamation between the 1980s and the early 1990s also reached its peak (Fig. 3). Most of the reclaimed land was used for agricultural purposes, such as paddy fields, fishponds and cropland, to support local industrial development. These early large-scale reclamation projects were approved by the Ministry of Water Resources, but none of them obtained a permit for ocean use from the State Oceanic Administration nor evaluated environmental and ecological effects. This scenario threatened local ecological sustainability. A series of environmental regulations, such as the Eight Prohibitions for Environmental Protection, legislated in 1992, were legitimised. This legislation proposed numerous 
prohibitions to improve the quality of the natural environment. For instance, buildings that exceeded $25 \mathrm{~m}$ above the hillside, less than $30 \mathrm{~m}$ approaching the riverbank or $50 \mathrm{~m}$ along the estuary bank were prohibited. Noise higher than 45 decibels was also forbidden to nurture a quiet and peaceful environment. Other regulations were made available to control pollution and carbon emission. This pro-environment mentality slowed Zhuhai's expansion rate. From 1995 to 2000, the expanded urban construction land area was 42.3\%, and from 1990 to 1995, the outlying growth declined. In Zhuhai's pursuit of a garden city, the city followed the policies of Singapore, a world renowned model for learning environment-friendly initiatives such as vegetation planting (Orff, 2001). Adopting these practices were important to strengthen the role of Zhuhai as an ecologically sustainable pioneer in PRD. The idea of an eco-city protected urban landscapes and environments. It also transformed Zhuhai into a liveable garden city. Zhuhai's economy was overshadowed by Shenzhen and Guangzhou, but Zhuhai's pleasant environment showcased its achievements in eco-city building and were in favour of the city's long-term sustainability.

High-tech industrial development was integrated into Zhuhai's pro-environment strategy, in which eco-sustainability and urban growth became interdependent. Zhuhai was a fishing village with a weak technological foundation; it started to develop as a hightech city in the early 1990s. The local government invested over one billion yuan to build Zhuhai University Town to attract science and technology talents. The college students and talents played a large role in Zhuhai's high-tech development, especially in the growth of industrial parks. Built in 1992, the Zhuhai National High-Tech Industrial Development Zone expanded in 1999, nurtured several high-tech firms and generated considerable output values. High-tech city development balanced economic growth and ecological sustainability. This development also played a positive role in the sustainable development of Zhuhai.

\section{Ecological landscape steering sprawl balance and typologies}

The ecological landscape of Zhuhai is significant to determine the typologies and (im)balance of urban land sprawl. Zhuhai's distinctive mountainous terrain fosters initial sprawl surrounding the boundary of mountains and hills. From 1980 to 1990, urban land around the Fenghuang and Banzhang mountains in the Xiangzhou District expanded prominently and was mainly characterised by edge expansion. In the Doumen District, areas along the Huangyang mountains were urbanised mostly with edge expansion as the main form supplemented by infill growth. Some sporadic expansion took place around other small hills, and the mountain-oriented expansion persisted until the early 2000s. Zhuhai grew in harmony with its natural surroundings and captured the idea of an eco-city. Thus, Zhuhai strategically selected eco-city as its development model. Unlike numerous Chinese cities, Zhuhai did not destroy mountains for expansion. Its sprawl is fast and rational. Given that Xiangzhou and Doumen county centres were naturally developed around green mountains, this type of infill growth also emerged occasionally in matured built-up areas. This scenario was particularly evident from 1990 to 2000 .

The coastal landscape enriches Zhuhai's sprawl, and this land reclamation has lasted until today. Reclamation creates new land over oceans, riverbeds or lakebeds. As a key mechanism accommodating urban growth, reclamation is popular in many harbour cities $(\mathrm{Ng}, 2011)$. Zhuhai has been reclaiming land for years and remains keen on expanding over the waters. Most of the reclamation took has taken place in Jinwan District and Hengqin Island. Coastal reclamation in the first decade was tremendous, with $108.4 \mathrm{~km}^{2}$ 
area having been infilled. However, a considerable proportion of the reclamation was not for urban growth but for agricultural use, thus aligning with Zhuhai's policies for sustainability in its early reform period. These reclamation activities result from an integrated thinking toward ecology and socioeconomic development, maximising the benefits that can be brought to local development and minimising the damage to local sustainability. In the early 1990s, Hengqin was recognised as one of the four key development zones by the Guangdong provincial government, for which the land area almost doubled by reclamation. This change has propped up the upscaling of Hengqin as a national new area. In 2013, the State Council approved to reclaim an approximately $20-\mathrm{km}^{2}$ seaside land area in Jinwan, creating new land for competitive industrial development, such as a yacht base and for the aviation industry. In 2015, the adjustment of the Hengqin Ocean Functional and Reclamation Plan was approved, granting $27.9 \mathrm{~km}^{2}$ more reclamation quotas in South Hengqin. This reclamation largely resolved the land resource constraints for free trade zone. Given the negative ecological impacts, the municipal government launched several rounds of environmental evaluation before project delivery to mitigate its adverse effects on nature. Harbour reclamation was part of Zhuhai's marine urban economic strategy. However, the cost and benefits of its reclamation are difficult to determine. Moreover, the ecological consequences of the reclamation also prompted substantial concerns from experts, scholars and officials. Large-scale reclamation is detrimental to sustainability in the long run and should best be practiced with caution in the future.

Geolocation is also influential. Similar to Shenzhen bordering Hong Kong, Zhuhai is close to Macau. However, Macau is not as competitive as Hong Kong; its tiny economic scale hardly benefits Zhuhai. This circumstance partly explains why Zhuhai did not follow Shenzhen's targeted strategy for industrialisation and why the city turned to ecocity development. Nevertheless, this difference did not prevent Zhuhai's cross-border land sprawl. From 1980 to 1990, Zhuhai started its urban land sprawl near Macau, mainly in the form of edge expansion supplemented by outlying growth. In all the increased $48.79 \mathrm{~km}^{2}$ area in the first decade, more than $29 \mathrm{~km}^{2}$ was in Xiangzhou District, which borders Macau. Land sprawl in Hengqin also benefitted from Zhuhai's cross-border location. In the early stage, Hengqin grew extremely slowly but cross-border vantage helped this area gain particular attention from the central government. In 2009, Hengqin was upgraded to a national new area, and its growth reached a peak of $4.62 \mathrm{~km}^{2}$ from 2010 to 2013 and $2.41 \mathrm{~km}^{2}$ in a short period between 2013 and 2015.

\section{Conclusion}

In deploying technical tools of remote sensing and GIS, this article investigates the general change of urban built-up area in the hinterlands and reclamation in the coast of Zhuhai, an ordinary large city in China's PRD region. It unravels spatiotemporal characteristics of urban land sprawl and discusses how the land of Zhuhai evolves under citywide pro-environment policies/discourses. The results corroborate that Zhuhai's urban land has expanded $1.06 \%$ annually for the past 35 years. Furthermore, the sudden growth of urban built-up area in total and per capita in 1995 (Fig. 2) was interpretable from local, regional, and national levels. At the local level, Zhuhai airport was officially built into navigation. As most advanced and modern airports at that time, Zhuhai airport not only racked up air passage between the city and other parts of China but also drove local construction profoundly. At the regional level, industrial investment from Hong 
Kong to PRD reached 25.2 billion HKD in 1995, leading to massive industrialisation in PRD. Regional urbanisation driven by this type of industrialisation has brought considerable growth opportunities for cities in PRD. At the national level, the number of cities experienced a surge from 193 in 1978 to 622 in 1994. With the huge influx of rural immigrants, urban population reached 343 million in 1994 and imposed an urgent demand for urban construction. The urban sprawl slowed down in the last five years of the 1990s and accelerated again in the 2000s with the construction of new towns in the Western part of the city. The rate slowed down from 2008 to 2010 but accelerated again from 2010 to 2013 with the promotion of Hengqin to a national new area in 2009. The findings of Zhuhai's three typologies of sprawl confirm the following information. Firstly, edge expansion has dominated each period and is prominent along the boundary of mountains and hills. Secondly, enclave development zones and new towns contribute to outlying growth. Thirdly, infill, as a supplement, mainly appears in well-developed city centres and is less common than the other two. The rate and intensity of three typologies have varied over time.

This study contributes to the understanding of urban sprawl in high density, rail transit-oriented area beyond the 'American model' and provides a view on a modest growing city. Different from U.S. metropolitan areas or China's mega-/super-cities where rates of outlying or expansion are less significant (than infill) or even negative (Hamidi and Ewing, 2014; Li and Li, 2019), Zhuhai's sprawl remains dominated by edge expansion with infill playing a negligible role. It also offers a clearer picture of urban land sprawl inside a city. The growth of urban built-up areas is uneven inside Zhuhai. Outlying was most uneven from 1990 to 1995 with a CV of 1.93 The unbalance of infill reached its peak recently (2013-2015) with a CV of 2.24. Edge expansion is the least unbalanced typology reaching the minimum of $0.42 \mathrm{CV}$ from 2010 to 2013. The CV of arable land loss was higher and fluctuated greater than that of forest loss. The unbalance of arable land loss reached a peak from 2005 to 2008 with a CV of 0.87 . In addition, extent of intra-urban land sprawl imbalance significantly fluctuates because local urban sprawl is sensitive to policy makings from local political leaders who are frequently reposted under China's floating cadre appointment system (He et al., 2018). Leaders of each tenure are likely to propose new potential areas, leading to great variability of urban sprawl inside the city. This city-level pattern is distinct from the macro-level one that regional differences (among the east, west, central, and northeast) have long been well-noted and that the backward west region has long sprawled more extensive than the developed east.

Furthermore, Zhuhai's growth amount is not as resplendent as that in star cities, such as Shenzhen and Guangzhou. From 1980 to 2015, the expanded urban area in Zhuhai was only one-third of that in Shenzhen and half of that in Guangzhou. This prudential growth has prevented Zhuhai's natural ambience from damage and has led the city to embrace a sustainable garden city ideology. Without sacrificing the environment, Zhuhai has gained several awards nationally and internationally for its ecological merits since 1997. Furthermore, its specific sprawl trajectory sheds some light on policy implications. Firstly, a pro-environment policy may reconcile contradictions between ecological environment and urban growth. It distinguishes cities with ecological merits from others. Secondly, environmental policy suppresses urban land growth to preserve high-quality environments for sustainable long-term development, thereby reaching a compromise between environmental sustainability and urban land growth. Thirdly, growth typology, despite circumstantial differences, conforms with environmental development in which natural mountains, rivers, and harbours are of utmost respected. Zhuhai did not stagnate 
but developed at a slow pace, which brought the city's natural environment into play. This study argues to conduct more in-depth case studies to enrich the understanding of intra-urban sprawl patterns, especially those invisible land sprawl, in small to medium sized cities and relate local policy and politics with the interpretations of sprawl patterns. Future research can also benefit from quantifying conversion between urban built-up area and other land uses so that the sources of sprawl can be tracked and monitored.

Acknowledgements. The work is funded by the National Natural Science Foundation of China [Grant No. 51808391, 41601445, 41701189] and Open Projects Fund of Key Laboratory of Shanghai Urban Renewal and Spatial Optimization Technology [Grant No. 2019020202].

\section{REFERENCES}

[1] Akbari, H., Rose, L. S., Taha, H. (2003): Analyzing the land cover of an urban environment using high-resolution orthophotos. - Landscape \& Urban Planning 63(1): 1-14.

[2] Aniekwe, S., Igu, N. (2019): A Geographical Analysis of Urban Sprawl in Abuja, Nigeria. - Journal of Geographical Research 2(1): 13-19.

[3] Batty, M. (2002): Thinking about Cities as Spatial Events. - Environment and Planning Bplanning \& Design 29: 1-2.

[4] Bhatta, B., Saraswati, S., Bandyopadhyay, D. (2010): Urban Sprawl Measurement From Remote Sensing Data. - Applied Geography 30: 731-40.

[5] Budd, W. W. (1996): Land mosaics: The ecology of landscapes and regions: Richard T. T. Forman, Cambridge University Press, 1995, 632 pp. - Book review. Landscape \& Urban Planning 36(3): 229-231.

[6] Burgess, E. W. (1925): The Growth of the City. - In: Park, R. E., Burgess, E. W., McKenzie, R. (eds.) The City: Suggestions of investigation of Human Behavior in the Urban Environment. University of Chicago Press, Chicago.

[7] Chang, C. C., Lin, C. J. (2011): LIBSVM: a library for support vector machines. - ACM Transactions on Intelligent Systems and Technology 2(3): 1-27.

[8] Chen, J. (2016): Urban land expansion and the transitional mechanisms in Nanjing, China. - Habitat International 53: 274-83.

[9] Congalton, R., Green, K. (2009): Assessing the Accuracy of Remotely Sensed Data: Principles and Practices. - CRC Press, Boca Raton.

[10] Ding, J., Wang, K. (2018): Spatio-temporal evolution of industrial production space and its driving mechanisms in Pearl River Delta urban agglomeration. - Geographical Research 37(1): 53-66.

[11] Grainger, A. (1995): National Land Use Morphology: Patterns and Possibilities. Geography 80: 235-45.

[12] Hamidi, S., Ewing, R. (2014): A longitudinal study of changes in urban sprawl between 2000 and 2010 in the United States. - Landscape \& Urban Planning 128: 72-82.

[13] Harris, C. D., Ullman, E. L. (1945): The Nature of Cities. - Annals of the American Academy of Political \& Social Science 242: 7-17.

[14] He, S., Li, L., Zhang, Y., Wang, J. (2018): A Small Entrepreneurial City in Action: Policy Mobility, Urban Entrepreneurialism, and Politics of Scale in Jiyuan, China. - International Journal of Urban and Regional Research 42(2): 286-302.

[15] Herold, M., Goldstein, N. C., Clarke, K. C. (2003): The spatiotemporal form of urban growth: measurement, analysis and modeling. - Remote Sensing of Environment 86: 286302.

[16] Hoyt, H. (1939): The Structure and Growth of Residential Neighborhoods in American Cities. U.S. - Government Printing Office, Washington. 
[17] Leichenko, R. M., Solecki, W. D. (2005): Exporting the American Dream: The Globalization of Suburban Consumption Landscapes. - Regional Studies 39(2): 241-253.

[18] Li, W., Wang, Y., Peng, J., Li, G. (2004): Landscape spatial changes in Shenzhen and their driving factors. - Journal of Applied Ecology 15: 1403.

[19] Li, G., Li, F. (2019): Urban sprawl in china: differences and socioeconomic drivers. Science of The Total Environment 673: 367-377.

[20] Liu, X., Li, X. Y., Chen, Y., Tan, Z., Li, S., Ai, B. (2010): A new landscape index for quantifying urban expansion using multi-temporal remotely sensed data. - Landscape Ecology 25(5): 671-682.

[21] Liu, T. (2020): China's Urban Construction Land Development. - Springer, Singapore.

[22] Long, H., Li, T. (2012): The coupling characteristics and mechanism of farmland and rural housing land transition in China. - Journal of Geographical Sciences 22: 548-62.

[23] Ng, M. K. (2011): Power and rationality: the politics of harbour reclamation in Hong Kong. - Environment and Planning C-government and Policy 29: 677-92.

[24] Orff, K. (2001): Great leap forward. - In: Chung, C. J., Inaba, J., Koolhaas, R., Leong, S. T. (eds.) Great leap forward / Harvard Design School Project on the city. Koln.

[25] Peng, J., Wang, Y., Zhang, Y., Wu, J., Li, W., Li, Y. (2010): Evaluating the effectiveness of landscape metrics in quantifying spatial patterns. - Ecological Indicators 10: 217-23.

[26] Qi, Z., Yeh, A. G. O., Li, X., Lin, Z. (2012): A novel algorithm for land use and land cover classification using RADARSAT-2 polarimetric SAR data. - Remote Sensing of Environment 118: 21-39.

[27] Scheuer, S., Haase, D., Volk, M. (2016): On the Nexus of the Spatial Dynamics of Global Urbanization and the Age of the City. - Plos One 11(8): e0160471.

[28] Shahraki, S. Z., Sauri, D., Serra, P., Modugno, S., Seifolddini, F., Pourahmad, A. (2011): Urban sprawl pattern and land-use change detectionin Yazd, Iran. - Habitat International 35: 521-528.

[29] Shi, Y., Sun, X., Zhu, X., Li, Y., Mei, L. (2010): Characterizing growth types and analyzing growth density distribution in response to urban growth patterns in peri-urban areas of Lianyungang City. - Landscape \& Urban Planning 98: 425-33.

[30] Theobald, D. M. (2001): Land-Use Dynamics beyond the American Urban Fringe. Geographical Review 91: 544-64.

[31] Xian, S., Li, L., Qi, Z. (2019): Toward a sustainable urban expansion: A case study of Zhuhai, China. - Journal of Cleaner Production 230: 276-85.

[32] Yang, Y., Liu, Y., Li, Y., Du, G. (2018): Quantifying spatio-temporal patterns of urban expansion in Beijing during 1985-2013 with rural-urban development transformation. Land Use Policy 74: 220-30.

[33] You, H. (2016): Quantifying megacity growth in response to economic transition: A case of Shanghai, China. - Habitat International 53: 115-22. 